\title{
Uncovering the affective turmoil during opportunity recognition and exploitation: A nonlinear approach
}

\author{
Susana C. Santos a,e, , António Caetano ${ }^{\mathrm{b}, \mathrm{e}}$, Sílvia F. Costa ${ }^{\mathrm{c}, \mathrm{e}}$, Rita Rueff Lopes ${ }^{\mathrm{d}}$, \\ Ana Junça Silva ${ }^{\mathrm{b}, \mathrm{e}}$, Xaver Neumeyer ${ }^{\mathrm{f}}$ \\ ${ }^{a}$ Rowan University, Rohrer College of Business, Business Hall, 201, Mullica Hill Rd, Glassboro, NJ, 08028, USA \\ ${ }^{\mathrm{b}}$ APPsyCI (Applied Psychology Research Center Capabilities and Inclusion - ISPA), Lisbon, Portugal \\ ${ }^{\mathrm{c}}$ University of Groningen Centre of Entrepreneurship, University of Groningen, Groningen, the Netherlands \\ ${ }^{\mathrm{d}}$ ESADE Business School, Universitat Ramon Llull, Barcelona, Spain \\ ${ }^{\mathrm{e}}$ Business Research Unit (BRU-IUL), ISCTE - Instituto Universitário de Lisboa, Lisbon, Portugal \\ ${ }^{\mathrm{f}}$ University of North Carolina at Wilmington, Wilmington, NC, USA
}

\section{A R T I C L E I N F O}

\section{Keywords:}

Affect

Opportunity recognition and exploitation

Nonlinear methods

\begin{abstract}
A B S T R A C T
This study explores the affective turmoil experienced by nascent entrepreneurs during opportunity recognition and exploitation. Based on the affect circumplex model, we employed nonlinear methods to identify configurations of affect that emerge during these early stages of the entrepreneurial journey. We analyzed data from 50 nascent entrepreneurs using Artificial Neural Networks (ANNs) trained with twenty affect dimensions as input variables and opportunity recognition and opportunity exploitation as outcomes. Results show that nascent entrepreneurs experience different affect configurations during opportunity recognition and exploitation. While four configurations of affect emerged associated with opportunity recognition and exploitation, their nature and importance to the experienced event are significantly different. Specifically, "active screening" is the most important configuration of affect during opportunity recognition, while "vigilant" is the most important during opportunity exploitation. We posit that nonlinear methods can help to uncover the affective turmoil experienced by entrepreneurs during a particular event. These findings provide new insights on how affect associates differently with cognition during the early stages of entrepreneurship.
\end{abstract}

“(...) a startup puts you on an emotional rollercoaster unlike anything you have ever experienced. You flip rapidly from day-today - one where you are euphorically convinced you are going to own the world, to a day in which doom seems only weeks away and you feel completely ruined, and back again. Over and over and over. (...)"

Marc Andreessen - Netscape, A16Z

\section{Introduction}

Entrepreneurship is a rollercoaster of affect, subjecting the entrepreneur to a broad range of subjective feeling states, moods and

\footnotetext{
* Corresponding author. Rowan University, Rohrer College of Business, Business Hall, 201, Mullica Hill Rd, Glassboro, NJ, 08028, USA.

E-mail addresses: santossc@rowan.edu (S.-M.P."S.C.S."a,e".N.field.K.field.->a.C. Santos), antonio.caetano@iscte.pt (A. Caetano), s.m.costa@rug. nl (S.F. Costa), rita.rueff@esade.edu (R. Rueff Lopes), ana_luisa_silva@iscte-iul.pt (A.J. Silva), neumeyerx@uncw.edu (X. Neumeyer).
} 
emotions (Baron and Tang, 2011). As affect is "antecedent to, concurrent with, and/or a consequence of the entrepreneurial process, meaning the recognition/creation, evaluation, reformulation, and/or the exploitation of a possible opportunity" (Cardon et al., 2012, p. 3), its role in venturing activities has inspired noteworthy scholarly work (e.g., Davis et al., 2017; Zampetakis et al., 2017). Yet, extant work on affect in entrepreneurship displays discrepancies (see systematic review García et al., 2015; Fodor and Pintea, 2017), and mainly adopts a positive or negative conceptualization of affect. This valence-based approach may not provide a holistic empirical demonstration of how entrepreneurs experience their feelings.

Prior research on the role of affect in entrepreneurship builds of traditional analytical methods, like multiple regression analysis and structural equation modeling. These methods assume symmetric central tendency and require data normally distributed around its mean, such that the relations between variables can be interpreted as linear dependencies (e.g. Douglas et al., 2020). Beyond the prospective linearity in some aspects, the entrepreneurial journey is about turbulence, uncertainty, change, and unstable leaps. While linear methods are valuable for testing hypotheses about presumed causal relationships underlying entrepreneurship, they leave significant shortcomings in our understanding of many nonlinear aspects of the entrepreneurial phenomenon, such as those related to the role of affect in entrepreneurship. Thus, there is a need for complementary analytical tools to capture the nonlinear nature of these relationships. As Churchill and Bygrave (1990) advise, "if we want to understand entrepreneurship, our research methodology must be able to handle nonlinear, unstable discontinuities" (p. 28).

There are three arguments to support the use of a nonlinear methodology instead of a traditional linear approach. First, entrepreneurship is filled with unexpected, nonlinear actions (Lichtenstein, 1999) and complex causalities (McKelvey, 2004). While linear methods are based on the assumption that predictors cannot be highly correlated, in dynamic and complex systems such as entrepreneurship (McKelvey, 2004), the elements are intrinsically interdependent and nonlinear methods can capture this while mitigating multicollinearity. Second, in dynamic systems such as entrepreneurship, predictors can modify their meaning as a byproduct of their outcomes. This reciprocal relationship is best modeled with nonlinear methods as they are sensitive to interactive relations and account for the intrinsic endogeneity of phenomena (see Lorenz, 1993). Third, research always entails noise or error that can be based on several factors, ranging from the measurement strategy to the nature of the constructs. Nonlinear approaches analyze noise in order to find possible hidden patterns in the relationships under study, whereas linear regression tends to disregard it. Thus, nonlinear methods can be complementary to symmetrical linear analytical tools, as they provide a finer-grained representation of entrepreneurial phenomena and a more accurate empirical analysis for theory building. Nevertheless, nonlinear methods can be misused and it is important to caution that they are not appropriate for every area of entrepreneurship research.

In this study, we adopt nonlinear methods, specifically artificial neural networks (ANN), to explore configurations of affect experienced by nascent entrepreneurs during opportunity recognition and exploitation. Building on the affect circumplex model (Russell, 1980, 2003), we conceptualize affect as several configurations of both positive and negative valence and high and low arousal, resulting in a unique meaning and importance associated with the targeted event. Entrepreneurs experience affect in a complex and mixed way, which has critical implications for entrepreneurial attitudes (e.g., Zampetakis et al., 2017), and cognitive appraisals (Podoynitsyna et al., 2012). Thus, grouping affect in terms of positive or negative valence may be reductive, and the assumed linear pattern underlying the traditional analytic tools used in prior research might be responsible for explaining inconsistent findings (see systematic review García et al., 2015; Fodor and Pintea, 2017). We contend that nonlinear methods are able to more accurately provide a complex understanding of these mixed aspects of affect (e.g., Podoynitsyna et al., 2012; Zampetakis et al., 2017; Treffers et al., 2019), and how these configurations of affect influence cognition, decision-making and behavioral responses (Adolphs and Damasio, 2001; Baron, 2008; Damasio, 2018). Therefore, these configurations of affect might be meaningful and relevant to explain the phenomena of interest, in our case, opportunity recognition and exploitation.

Through this approach, this study makes two main contributions. First, we contribute to the entrepreneurship literature on the role of affect in entrepreneurial cognition (Baron, 2008; Ivanova et al., 2018) by demonstrating the importance of investigating affect as a configuration of both valence and arousal levels. Prior research on mixed emotions has shown the benefits of framing emotions according to a cognitive appraisal tendency approach rather than a valence-based one (Podoynitsyna et al., 2012). We extend this discussion by adding the affect circumplex model (Russell, 1980, 2003) as a framework to define configurations of affect. We also show that configurations of affect coexist during the early stages of entrepreneurship, and that they play a different role in opportunity recognition and exploitation. Second, we contribute to recent work that examines the complexities of entrepreneurship that are "left unexamined by traditional methods" (Douglas et al., 2020, p. 14). Using nonlinear methods, such as artificial neural networks, we are able to capture the complexitiy of affect experienced during opportunity recognition and exploitation, and provide additional clarity on how the affective turmoil shapes cognitive properties during the startup process. In doing so, we also answer to Shepherd's call (2015) to take an interactive perspective of entrepreneurial opportunities and being more "cognitively hot".

\section{Nascent entrepreneurs' affective experiences during opportunity recognition and exploitation}

Affect - referring both to dispositional and event generated affect, emotions, moods, and/or feelings (Baron and Tang, 2011; Cardon et al., 2012) - is closely intertwined with entrepreneurial cognition. As Zajonc (1980) noted, "the early affective reaction (...) is capable of influencing the ensuing cognitive process to a significant degree" (p. 154), and "in many decisions affect plays a more important role than we are willing to admit" (p. 155). Two conditions are particularly propitious for a significant impact of affect on entrepreneurial cognition and decision making (Baron, 1998, 2008; Forgas, 1995). First, opportunity recognition and exploitation occur under risky, unscripted and uncertain conditions that require entrepreneurs to act quickly and with limited information about complex matters (Baron, 1998, 2008; Forgas, 1995; Busenitz and Barney, 1997). Second, such early stage entrepreneurship activities require creativity, persuasion, evaluation, judgment, and forming productive working relationships, which are all activities strongly influenced by affect 
(Blanchette and Richards, 2010; Angie et al., 2011).

Entrepreneurs tend to recognize business opportunities ${ }^{1}$ by perceiving connections between apparently unrelated events or trends e.g., changes in technology, demographics, markets, or government policies - as a meaningful pattern (Baron, 2006; Grégoire et al., 2010), subsequently exploiting them and bringing ideas into reality (Eckhardt and Shane, 2003; Kuckertz et al., 2017). Prior scholarly work has focused on the effects of the valence of affect (positive and negative) on opportunity recognition and exploitation, as we respectively summarize below.

Positive affect as enthusiasm, joy or passion are emotional resources that entrepreneurs carry to deal with the challenges of early entrepreneurial activity (Cardon et al., 2009). These were found to benefit an individual's creativity and opportunity recognition (Baron et al., 2011; Hayton and Cholakova, 2012). Positive affect tends to signal that the current situation is unproblematic, hence favoring the occurrence of less organized, more fluid and effortless information processing, divergent thinking and novelty (Kaufmann, 2003). According to the broaden-and-build theory, positive emotions broaden thought-action tendencies as playing, exploring, savoring and integrating or envisioning future achievements (Fredrickson, 2001), which benefits opportunity recognition. Positive affect also promotes heuristics simplification and the implementation of integrative top-down strategies (George and Zhou, 2007), which helps a more comprehensive perception of the environment and underlying entrepreneurial opportunities. Positive affect is also associated with entrepreneurial alertness, while individuals experiencing negative affect are unable to exhibit the association, search, and evaluation capabilities inherent to alertness (Tang et al., 2012). Therefore, negative affect, on the other side, is detrimental to entrepreneurial performance, as it triggers counterproductive behaviors (Fodor and Pintea, 2017), hinders entrepreneurial motivation (Doern and Goss, 2014), and harms creativity, resulting in fewer opportunities recognized (Hills et al., 1999). Overall, the more positive affect a nascent entrepreneur experiences, the more likely he/she will recognize an opportunity, while the experience of negative affect will harm opportunity recognition.

Opportunity exploitation entails all the activities towards launching the venture (Baron and Ensley, 2006). A systematic literature review showed that the role of affect in opportunity exploitation has been contradictory (García et al., 2015), which may be due to the higher level of rationality required to the decision in whether to exploit it or not (McMullen and Shepherd, 2006). While Kuckertz et al. (2017) found that positive affect is positively associated with opportunity exploitation, negative affect showed to be unrelated. Yet, when students and entrepreneurs engaged in an experiment with entrepreneurial scenarios, fear was found to decrease entrepreneurial exploitation, whereas joy and anger increased exploitation tendencies (Grichnik et al., 2010; Welpe et al., 2012). As the decision to exploit an opportunity is based on both feasibility and desirability assessments (Santos et al., 2015), different cognitive-emotional mechanisms play a role in the appraisal tendency (Foo, 2011; Podoynitsyna et al., 2012). Specifically, anger, fear and happiness influence the desirability dimension but not feasibility (Ivanova et al., 2018). These diverse findings demonstrate how it is important to capture the complex, multidimensional nature of affect and their effect upon decision making (So et al., 2015).

We challenge prior work by advocating that nascent entrepreneurs do not experience affect in terms of a dichotomic valence ("positive" or "negative"). While extant research "take the average value of positive and negative affect respectively and use them to predict entrepreneurial outcomes" (Uy et al., 2017, p. 444) and offer many insights about the role of affect in entrepreneurship, they tend to overlook the richness of entrepreneur's affect configurations experienced during an event. Entrepreneurs experience emergent affect comprised of a unique configuration of both valence (positive and negative) and arousal (high and low), but traditional linear data analysis methods struggle in capturing such complexity.

We frame this proposition according to the circumplex model of affect (Russell, 1980, 2003) defined on two axes. The pleasure-displeasure axis identifies the valence feature (i.e., positive or negative), and the activation-deactivation axis indicates the high versus low arousal component (Remington et al., 2000). Drawing on this circumplex framework (Russell, 1980, 2003), affect in work settings (here, entrepreneurship related) can be defined in a four-quadrant perspective by crossing the two axes: high-activation pleasant affect (HAPA); low-activation pleasant affect (LAPA); high activation unpleasant affect (HAUA); and low-activation unpleasant affect (LAUA) (Warr et al., 2014). Affect associated with specific events are located along the continuum of the circumplex (Remington et al., 2000).

These emergent configurations of affect are idiosyncratic, i.e., they are specific to the experienced event or episode. This means that the configurations of affect emerging while nascent entrepreneurs recognize opportunities is likely to be different from those emerging when they are actively exploiting the opportunity. We expand on this below in two ways. First, nascent entrepreneurs experience affect with different valence during opportunity recognition and exploitation (Welpe et al., 2012). This suggests that the configurations of affect associated with recognition and exploitation will display distinctive positionings along the pleasure-displeasure axis. Second, affect has a different impact on cognition and decision-making, depending on the nature of the activities required (Baron, 2008; Tang et al., 2012). As opportunity recognition and exploitation are two distinct stages with unique cognitive demands (Santos et al., 2015; Kuckertz et al., 2017) and affective reactions may become separated from content (Zajonc, 1980), the configurations of affect associated with each one are likely to be different. Therefore, we hypothesize that nascent entrepreneurs experience different configurations of affect during opportunity recognition and exploitation.

\footnotetext{
1 Entrepreneurial opportunities are "situations in which new goods, services, raw materials, and organizing methods can be introduced and sold at greater than their cost of production" (Shane and Venkataraman, 2000, p. 220).
} 


\section{Method}

\subsection{Sample, data collection and measures}

Fifty nascent entrepreneurs (i.e., individuals who were actively involved in launching a business) participated in this study. The entrepreneurs were invited to join this study through a national entrepreneurship association in a European country, who asked the qualified individuals to voluntarily answer a survey online (response rate of 65.5\%). Entrepreneurs were mainly male (60\%), the mean age was 39.68 years ( $S D=10.15$ ), $46 \%$ completed a masters' degree, $32 \%$ graduated from college (undergraduate degree), and $22 \%$ completed a doctoral degree. Startup companies operated in diverse industries, as technology and software, industrial and systems engineering, food and beverages, educational and cultural services, and financial services.

Entrepreneurs were asked to retrospectively recall their early stages of the entrepreneurial experience when they recognized the opportunity, defining the business concept, gathering information about the viability of the business model, and deciding whether to pursue further their business. This recall procedure has been used both in opportunity recognition studies (e.g., Baron and Ensley, 2006) and affective states research (e.g., Grichnik et al., 2010) in entrepreneurship (Hayton and Cholakova, 2012). Opportunity recognition was measured using five items adapted from Baron and Ensley (2006): "The business idea meets needs"; "It can change the market"; "It relieves any painful situation", "It can do more", and "It can be a big player product". The opportunity recognition items were preceded by the instruction "Having in mind your business idea, indicate to what extent each of the following aspects was important to you in identifying your business opportunity".

Opportunity exploitation was measured by the proxy of decision to launch a venture with five items also adapted from Baron and Ensley (2006): "I had positive assessment from a legal council"; "I had positive assessment from a consultant"; "I had positive assessment from financial advisors"; "My friends told me it was a good idea"; and "It has a short sales cycle idea". The opportunity exploitation items were preceded by the instruction "Having in mind your business idea, indicate to what extent were the following aspects important to your decision to implement your project/business". Both opportunity recognition and exploitation items were assessed on a seven-point scale, ranging from 1 "not important at all" to 7 "very important".

Affect dimensions were measured by using the twenty items Positive and Negative Affect Schedule scale (PANAS) developed by Watson et al. (1988). The items were preceded by an instruction asking participants to recall how they were feeling in the months when they were deeply involved and working on the early entrepreneurship stages (i.e., when recognizing the opportunity, defining the business concept, gathering information about the viability of the business model, etc.). The items were assessed on a five-point scale ranging from 1 "never" to 5 "always". Table 1 presents the descriptive statistics and the correlation matrix.

\subsection{Data analysis: artificial neural networks (ANNs)}

The relationships between the variables of interest in the present study were modeled using ANNs, a branch of data mining that allows the modeling of a complex system by decomposing it on its simpler elements (e.g., Yegnanarayana, 2009). ANNs imitate the way human brain works and combine features that resemble the structure of the neurons, associative memory and correlational learning (Karanika-Murray and Cox, 2010). They consist of input nodes that receive the predictor variables just like the neurons receive messages from the synapses. Likewise the human brain that generally works with multiple thoughts (the inputs), the neural network works with multiple vectors (input nodes). An ANN consist of (a) an input layer of simple nodes that receive external stimuli (in this study, the input variables are the positive and negative affect); (b) a hidden layer where relationships between the input and output layer are stored; and (c) an output layer of outcome (in this study, the outcome variables are opportunity recognition and opportunity exploitation). ANNs form hidden nodes that enable the identification and removal of correlations among variables allowing for dimensionally reduction (Rueff-Lopes et al., 2017). Information about each input's level of activation or importance is provided for the output, ranging from -1 (no importance) to 1 (maximum of importance). The activation of the hidden nodes is contingent upon the sum of its inputs and on the strength of its outputs. At this point, the values are multiplied by a weight and the results are added up and passed through a transfer function that originates the output values, which are then distributed to the output layer. In the output layer, the values of each node are again multiplied by a weight and the final output is compared to the desired output.

For the analyses, we randomly divided the participants in two samples: 70\% assigned for training and 30\% allocated for testing (35/ 15 for $\mathrm{N}=50$ ). This procedure allows us to track the errors and to prevent over-training (e.g., Karanika-Murray and Cox, 2010) and it was shown to be efficient in different studies working with small to medium sample sizes (e.g., 30/10 for N = 40 in Hui et al., 2004 ; $82 / 10$ for $\mathrm{N}=92$ in Li et al., 2011). Regarding the type of training, we used the batch training method because it reduces the total error and is more accurate for small to medium datasets. With regard to stopping rules, we allowed one additional step (i.e., the repetition of the training method) when error stopped decreasing. To facilitate replication, we used a specific initialization value for the random number generator.

We trained two models of artificial neural networks using the statistics program R and the NeuralNet package (Fritsch et al., 2016). Both included the 20 affect items in the input layer. As output variables, the first model (ANN1) included opportunity recognition, and the second model (ANN2) included opportunity exploitation. Architecturally, the best solution for both ANNs was a 20-4-1 structure (see Fig. 1), with 20 predictive variables (or nodes in the input layer), four nodes in the hidden layer, and one criterion variable. The Olden algorithm (see Olden et al., 2004) was computed to evaluate the prevalence of each affect dimension in opportunity recognition and opportunity exploitation. This method calculates "the importance as the summed product of the raw input-hidden and hidden-output connection weights between each input and output node. An advantage is that the relative contributions of each connection weight are maintained in both magnitude and sign. (...) An additional advantage is that the olden function can evaluate 
Table 1

Descriptive statistics and correlation matrix of the variables of interest.

\begin{tabular}{|c|c|c|c|c|c|c|c|c|c|c|c|c|c|c|c|c|c|c|c|c|c|c|c|}
\hline & $\Sigma$ & के & ir & i & $\dot{m}$ & $\dot{+r}$ & in & 6 & $i$ & $\infty$ & $\sigma^{\circ}$ & $\dot{9}$ & $\dot{I}$ & $\stackrel{\text { I }}{ }$ & $\dot{m}$ & $\dot{I}$ & ம் & $\stackrel{\dot{\varphi}}{ }$ & $\therefore$ & $\stackrel{\infty}{\oplus}$ & 9 & ì & $\overrightarrow{\mathrm{N}}$ \\
\hline 1. OR & 4.04 & 0.47 & $\underline{0.84}$ & & & & & & & & & & & & & & & & & & & & \\
\hline 2. $\mathrm{OE}$ & 3.46 & 0.52 & $\overline{0.49^{* * *}}$ & $\underline{0.81}$ & & & & & & & & & & & & & & & & & & & \\
\hline 3. Interested & 4.30 & 0.84 & 0.12 & $\overline{0.01}$ & & & & & & & & & & & & & & & & & & & \\
\hline 4. Distressed & 3.34 & 1.61 & 0.18 & 0.06 & $-0.33^{*}$ & & & & & & & & & & & & & & & & & & \\
\hline 5. Excited & 3.56 & 1.40 & -0.02 & 0.13 & $0.37^{*}$ & $-0.38^{*}$ & & & & & & & & & & & & & & & & & \\
\hline 6. Upset & 2.62 & 1.82 & 0.15 & 0.20 & $-0.34^{*}$ & $0.78^{* * *}$ & $-0.28^{*}$ & & & & & & & & & & & & & & & & \\
\hline 7. Strong & 3.32 & 1.72 & 0.07 & $0.34^{*}$ & 0.24 & -0.02 & $0.37^{*}$ & -0.01 & & & & & & & & & & & & & & & \\
\hline 8. Guilty & 2.50 & 1.75 & 0.29 & $0.33^{*}$ & -0.22 & $0.62^{* * x}$ & -0.19 & $0.81^{* * *}$ & 0.21 & & & & & & & & & & & & & & \\
\hline 9. Scared & 2.20 & 1.71 & 0.06 & 0.37 & 0.09 & 0.26 & 0.27 & $0.30^{*}$ & $0.64^{\text {** }}$ & $0.48^{\text {** }}$ & & & & & & & & & & & & & \\
\hline 10. Hostile & 2.08 & 1.76 & -0.01 & 0.24 & -0.09 & $0.54^{* * *}$ & 0.03 & $0.66^{* * *}$ & 0.23 & $0.64^{* *}$ & $0.58^{* * *}$ & & & & & & & & & & & & \\
\hline 11. Enthusiastic & 3.50 & 1.80 & -0.03 & 0.24 & $0.48^{* *}$ & $-0.40^{* * *}$ & $0.71^{\text {** }}$ & $-0.39^{*}$ & $0.61^{\text {k* }}$ & -0.14 & $0.47^{* * *}$ & 0.11 & & & & & & & & & & & \\
\hline 12. Proud & 4.24 & 0.87 & 0.25 & 0.13 & 0.01 & $0.29^{*}$ & 0.24 & $0.36^{*}$ & 0.25 & $0.41^{\text {*** }}$ & 0.24 & 0.23 & 0.04 & & & & & & & & & & \\
\hline 13. Irritable & 2.82 & 1.66 & 0.24 & 0.27 & -0.22 & $0.63^{* *}$ & -0.20 & $0.84^{* *}$ & 0.05 & $0.85^{\text {** }}$ & $0.29^{*}$ & $0.65^{\text {** }}$ & $-0.30^{*}$ & $0.41^{\text {k*k }}$ & & & & & & & & & \\
\hline 14 Alert & 3.28 & 1.59 & 0.11 & 0.21 & 0.23 & -0.14 & $0.46^{\text {***}}$ & -0.03 & $0.65^{* k}$ & 0.26 & $0.65^{* * *}$ & $0.29^{*}$ & $0.67^{* * *}$ & 0.27 & 0.07 & & & & & & & & \\
\hline 15. Ashamed & 2.54 & 1.74 & 0.13 & 0.24 & $-0.32^{*}$ & $0.74^{* * *}$ & -0.22 & $0.86^{* \star}$ & -0.01 & $0.75^{\text {** }}$ & $0.37^{*}$ & $0.77^{\text {*** }}$ & $-0.32^{*}$ & $0.29^{*}$ & $0.86^{* * *}$ & 0.04 & & & & & & & \\
\hline 16. Inspired & 3.58 & 1.77 & 0.12 & 0.24 & $0.51^{\text {k* }}$ & $-0.30^{*}$ & $0.59^{* *}$ & $-0.29^{*}$ & $0.79^{* \star *}$ & -0.02 & $0.61^{* * *}$ & 0.09 & $0.83^{* * *}$ & 0.17 & -0.21 & $0.77^{* * *}$ & -0.24 & & & & & & \\
\hline 17. Nervous & 3.42 & 1.39 & 0.18 & 0.18 & -0.20 & $0.65^{* *}$ & -0.17 & $0.75^{\text {** }}$ & 0.05 & $0.75^{\text {k* }}$ & $0.38^{*}$ & $0.55^{\text {** }}$ & $-0.31^{*}$ & $0.44^{\text {*** }}$ & 0.82 & 0.08 & 0.77 & -0.18 & & & & & \\
\hline 18.Determinated & 3.98 & 1.29 & 0.07 & -0.06 & $0.40^{* * *}$ & $-0.29^{*}$ & $0.64^{* *}$ & $-0.38^{*}$ & $0.34^{*}$ & -0.19 & 0.14 & -0.04 & $0.58^{* * *}$ & $0.31^{*}$ & -0.22 & $0.37^{7 * k}$ & $-0.29^{k}$ & $0.52^{k *}$ & -0.21 & & & & \\
\hline 19. Attentive & 4.38 & 0.88 & $0.35^{*}$ & 0.13 & 0.26 & $0.28^{*}$ & 0.20 & $0.45^{* *}$ & 0.27 & $0.55^{* * *}$ & $0.33^{*}$ & 0.32 & 0.11 & $0.63^{* *}$ & $0.51^{* * k}$ & $0.45^{* *}$ & $0.41^{* * *}$ & 0.22 & $0.57^{* *}$ & $0.28^{*}$ & & & \\
\hline 20. Jittery & 3.24 & 1.51 & -0.02 & -0.14 & -0.18 & $0.55^{* *}$ & -0.22 & $0.56^{* \star *}$ & -0.01 & $0.59^{* * *}$ & $0.28^{*}$ & $0.38^{*}$ & -0.25 & $0.43^{* *}$ & $0.59^{* * *}$ & 0.06 & $0.52^{* \star *}$ & -0.16 & $0.78^{* *}$ & -0.25 & $0.40^{* * *}$ & & \\
\hline 21. Active & 4.22 & 1.43 & 0.18 & 0.11 & 0.13 & 0.10 & 0.04 & 0.04 & $0.41^{\text {** }}$ & 0.17 & $0.37^{*}$ & 0.08 & $0.29^{*}$ & 0.24 & 0.03 & $0.52^{\star *}$ & 0.00 & $0.41^{\text {k* }}$ & 0.08 & 0.18 & $0.33^{* * *}$ & 0.24 & \\
\hline 22. Afraid & 3.27 & 1.40 & 0.09 & 0.11 & $-0.31^{*}$ & 0.60 & -0.19 & $0.75^{* \star *}$ & 0.00 & $0.68^{* *}$ & $0.35^{*}$ & $0.55^{* *}$ & $-0.31^{*}$ & $0.45^{\text {** }}$ & $0.76^{* * *}$ & 0.07 & $0.70^{* * *}$ & -0.25 & $0.87^{7 * *}$ & -0.26 & $0.47^{* * *}$ & $0.76^{* * \hbar}$ & 0.14 \\
\hline
\end{tabular}



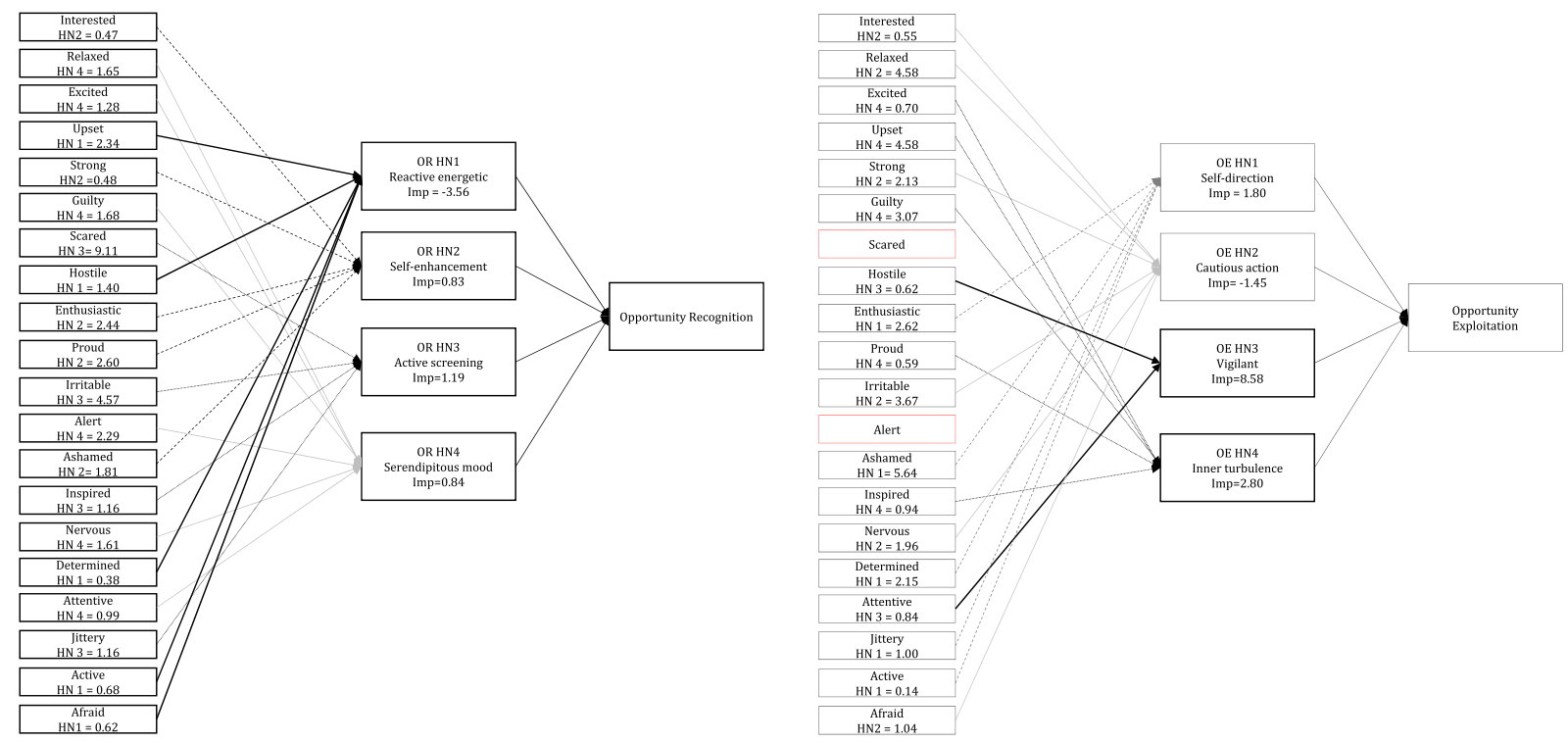

Fig. 1. Plot of the Artificial Neural Networks (ANN) for opportunity recognition and exploitation.

neural networks with multiple hidden layers and response variables" (Beck, 2018, p. 7 and 8). The importance values should be interpreted based on the relative sign and magnitude between the predictors. This method has been shown to outperform others (e. g., the Garson method) in various simulations (Greenwell et al., 2018).

\section{Results}

The values of the averaged variance explained were very satisfactory for both models and significantly exceeded the variance explained using a traditional linear regression (ANN1: $\mathrm{R}^{2}$ opportunity recognition $=85 \%$; Multiple Linear Regression $\mathrm{R}^{2}$ opportunity recognition $=$ 31\%; ANN2: $\mathrm{R}^{2}{ }_{\text {opportunity exploitation }}=72 \%$, Multiple Linear Regression $\mathrm{R}^{2}{ }_{\text {opportunity exploitation }}=24 \%$ ) as expected since nonlinear models typically explain the more than double of variance comparing with their linear counterparts (Guastello, 2007).

\subsection{Labeling of the hidden nodes}

Fig. 1 displays the most important neural network connections for opportunity recognition and exploitation, respectively (see Appendix 1 and 2 for the contribution of each predictor to the hidden nodes in opportunity recognition and exploitation).

The hidden nodes (HN) show an association of affect that entrepreneurs experienced during the event, here opportunity recognition and exploitation. Each hidden node was labeled according to the positioning of its strongest contributors in the affect circumplex model (Russell, 2003; Warr et al., 2014). Specifically, we looked at the positioning of each affect dimension in the pleasure-displeasure axis, the activation-deactivation axis, and their contribution value. Fig. 2 shows a representation of the positioning of the HN in the affect circumplex model for opportunity recognition and exploitation.

\subsubsection{Opportunity recognition}

OR Hidden Node 1: Five inputs contribute to the OR HN1. Upset and hostile are the strongest contributors (Upset ${ }_{C o n t r i b .}=2.35$; Hostile Contrib. $_{1.40}$ ), followed by active and afraid (Active Contrib. $=0.68$; Afraid Contrib. $_{1}=0.62$ ) and determined (Determined Contrib. $=$ 0.38). The positioning of these inputs in the affect circumplex model (Fig. 2) includes two in the HAPA quadrant (determined and active), two in the HAUA quadrant (afraid and upset) and one in the LANA quadrant (hostile). An intrinsic dissonance characterizes this configuration of affect. There is a feeling of reaction to an external condition, an active restless while being determined to act. We labeled the OR HN1 as "Reactive energetic". OR HN1 shows a negative relative importance to opportunity recognition (RI OR HN1 = -3.56), meaning that this affect configuration reduces individuals' tendency to continue recognizing opportunities.

OR Hidden Node 2: Five inputs contribute to the OR HN2. Proud, enthusiastic, strong and interested are located in the HAPA quadrant (Proud Contrib. $_{1}$ 2.60; Enthusiastic Contrib. $=2.44$; Strong Contrib. $=1.41$; Interested Contrib. $=0.48$ ), and ashamed is located in the LAUA quadrant (Ahsamed Contrib. $=1.81$ ). OR HN2 is associated with a motivational characteristic. Feeling proud, strong, enthusiastic and interested, the nascent entrepreneur seems to be enjoying the challenge inherent to opportunity recognition. Yet, this prevalence of high-activation high pleasure affect is intertwined with feeling ashamed, which is important to avoid narcissist behaviors and excessive illusion, which would be detrimental for opportunity recognition. We labeled OR HN2 "Self-enhancement" which shows relative importance of 0.83 .

OR Hidden Node 3: Three contributors to the OR HN3 are located in the HAUA quadrant (Scared Contrib. $=9.11$, Irritable Contrib. $=$ 

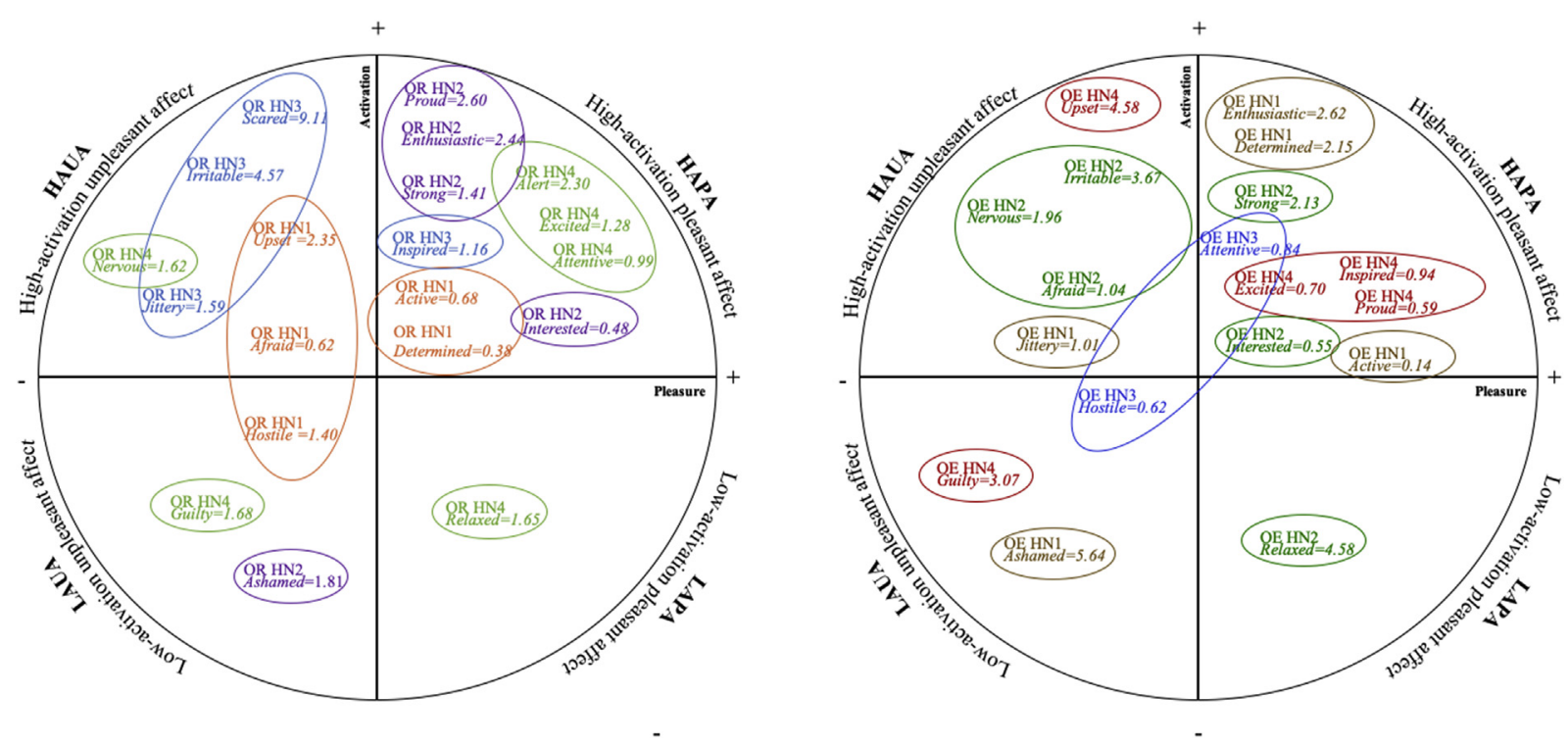

Fig. 2. Positioning of the hidden nodes in the affect circumplex model for opportunity recognition and exploitation. Note: Each affect dimension is labeled with its contribution to the hidden node. See appendix 1 for opportunity recognition and appendix 2 for opportunity exploitation.

4.57 , and Jittery Contrib. $=1.59$ ) while one item belongs to the HAPA quadrant (Inspired Contrib. $=0.48$ ). All the contributors to OR HN3 are situated in high arousal semi-circle of the affect circumplex model, showing that the nascent entrepreneur is feeling highly reactive while being inspired. We assume that the nascent entrepreneur is actively screening the environment, feverishly looking for the best opportunity to exploit. As such, we labeled OR HN3 as "Active screening" displaying the highest relative importance to opportunity recognition ( $R I$ OR HN3 $=1.19$ ), showing that this configuration of affect is the most relevant associated with individuals' tendency to recognize opportunities.

OR Hidden Node 4: Six elements contribute to the OR HN4: three are located in the HAPA quadrant (Alert Contrib. $=2.30$, Excited Contrib. = 1.28; and Attentive Contrib. $=0.99$ ), one in the HAUA quadrant (Nervous Contrib. $=1.62$ ), one in the LAUA quadrant (Guilty Contrib. $=1.68$ ), and one in the LAPA quadrant (Relaxed Contrib. =1.65). OR HN4 is the only HN comprising dimensions from the four quadrants. In this hidden node, the nascent entrepreneur feels attentive and excited, but at the same time, feels relaxed as there is no significant financial investment. Nascent entrepreneurs appear to be looking around for an accidental discovery. As such, we labeled OR HN4 as "Serendipitous mood". The relative importance of "Serendipitous mood" to opportunity recognition is 0.83.

\subsubsection{Opportunity exploitation}

OE Hidden Node 1: Five dimensions contribute to OE HN1. The strongest contributor is located in the LAUA quadrant (Ashamed

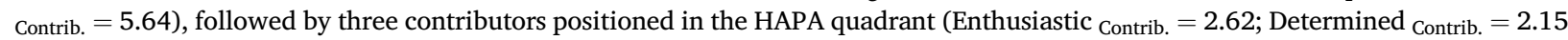
and Active Contrib. $=0.14$, while with a lower score), and one in the HAUA quadrant (Jittery Contrib. $=1.01$ ). A sense of action and determination characterizes this hidden node. Nascent entrepreneurs are acting towards their opportunities, feeling enthusiastic, determined and active, but also reluctant, hesitant and cautious. We labeled OE HN1 "Self-direction" having relative importance of 1.18 to opportunity exploitation.

OE Hidden Node 2: Six strongest contributors define OE HN2. The strongest contributor is positioned in the LAPA quadrant (Relaxed Contrib. $=4.58$ ), followed by three dimensions in the HAUA quadrant (Irritable Contrib. $=3.67$; Nervous Contrib. $=1.96$ and Afraid Contrib. $=$ 1.04), and lastly two dimensions located in the HAPA quadrant (Strong Contrib. $=2.13$ and Interested Contrib. $=0.55$ ). This configuration of affect displays a relative balance between feeling relaxed, but with a predominance of high-activation unpleasure affect as irritable, nervous and afraid. It demonstrates some reservations towards exploitation, while still strong and interested. We labeled OE HN2 as "Cautious action". This configuration of affect shows negative relative importance towards opportunity exploitation (RI $=-1.45$ ), meaning that "Cautious action" reduces individuals' tendency to continue exploiting the opportunity.

OE Hidden Node 3: The two strongest contributors that define OE HN3 include attentive, located in the HAPA quadrant (Attentive Contrib. $=0.84$ ), and hostile, positioned in the LAUA quadrant (Hostile contrib. $=0.62$ ). This diagonal configuration includes elements from two extreme opposites of the affect circumplex model. The emerged configuration of affect shows arousal disparity (high and low activation) and pleasure tension (positive and negative valence) simultaneously. This hidden node resembles to sentinel the nascent entrepreneur. OE HN3 is labeled "Vigilant" and has the highest relative importance to opportunity exploitation (RI OE HN3 = 8.58), showing that this configuration of affect is the most relevant to individuals' tendency to exploit opportunities.

OE Hidden Node 4: Five contributors define OE HN4. The strongest contributor is upset (HAUA quadrant, Upset Contrib. $=4.58$ ) followed by guilt (LAUA quadrant, Guilty Contrib. $=3.07$ ). Three affect dimensions emerge in the HAPA quadrant with lower contributions (Proud Contrib. $=0.59$, Inspired Contrib. $=0.94$ and Excited Contrib. $=0.70$ ). This hidden node is mainly characterized by 
Table 2

Olden algorithm for the relative importance of affective states to opportunity recognition and exploitation.

\begin{tabular}{lll}
\hline & Olden's algorithm for the Relative Importance & \\
\cline { 2 - 3 } & Opportunity Recognition & Opportunity Exploitation \\
\hline Active & -2.4 & -4.94 \\
Alert & 3.33 & -9.28 \\
Afraid & -10.13 & -7.44 \\
Ashamed & 6.98 & $\mathbf{1 5 . 3 9}$ \\
Attentive & 5.44 & 9.2 \\
Determined & -2.13 & $\mathbf{1 7 . 3 9}$ \\
Enthusiastic & -2.11 & 2.16 \\
Excited & 5.11 & -1.07 \\
Guilty & -0.67 & $\mathbf{2 8 . 5 3}$ \\
Hostile & -4.29 & 0.62 \\
Inspired & 3.25 & 6.15 \\
Interested & 7.03 & -13.84 \\
Irritable & $\mathbf{1 0 . 1 9}$ & -18.45 \\
Jittery & 0.09 & -3.54 \\
Nervous & -3.14 & -0.39 \\
Proud & 3.24 & -0.22 \\
Relaxed & -0.51 & -23.83 \\
Scared & $\mathbf{1 4 . 0 1}$ & 5.3 \\
Strong & 2.14 & 2.28 \\
Upset & -5.82 & -31.25 \\
\hline
\end{tabular}

Note: Bold values mark the highest raw input affective states to each output variable, opportunity recognition and exploitation.

perturbation and sentiment of guilt. Thus, we named OE HN4 "Inner turbulence", which has a relative importance of 2.80 to opportunity exploitation.

These results support our hypothesis, showing that the configuration of affect is different in opportunity recognition and exploitation. To provide a robustness check to our results, we computed the Olden algorithm, pertaining to evaluate the prevalence of each affect dimension in opportunity recognition and exploitation. The results revealed that the affect dimensions (raw input) with the highest relative importance to opportunity recognition are "scared" (OR RI OldenAlg $=14.01)$ and "irritable" $\left(O R \mathrm{RI}_{\mathrm{OldenAlg}}=10.19\right)($ first column of Table 2), both affect dimensions located in the HAUA quadrant. "Guilty" (OE RI $\mathrm{OldenAlg}_{2}=28.53$ ) had the highest importance to opportunity exploitation, followed by "determined" (OE RI OldenAlg $=17.39$ ) and "ashamed" (OE RI Table 2). Guilty and ashamed are positioned in the LAUA quadrant, and determined in the HAPA quadrant. We discuss the meaning and implications of these results in the next section.

\section{Discussion}

The affect-cognition link has received increased attention in the entrepreneurship literature (Baron, 2008; Shepherd and Patzelt, 2018). In this paper, we have highlighted the complexities of the configurations of affect experienced by nascent entrepreneurs during opportunity recognition and exploitation. To uncover such complexities, we used nonlinear methods, specifically artificial neural networks. Our study builds on recent arguments that traditional symmetric data analysis methods are not enough to understand the complexity of entrepreneurship (Douglas et al., 2020) and resolves prior inconsistencies about the affective experiences during the early stage of entrepreneurship (e.g. García et al., 2015; Fodor and Pintea, 2017).

Our nonlinear analysis revealed that nascent entrepreneurs experience several complex affect configurations comprising both pleasure-displeasure valence and high-low arousal. Plus, according to our expectations, the configurations of affect emerged during opportunity recognition and exploitation were different. We expand on this below.

Nascent entrepreneurs experience fairly complex affect configurations, including coexisting disparity of valence and activation levels (e.g. Podoynitsyna et al., 2012). Using the affect circumplex model (Russell, 1980, 2003; Warr et al., 2014), we framed the configurations of affect experienced during opportunity recognition. Nascent entrepreneurs feel "active screening", a "serendipitous mood" and "self-enhancement" while recognizing opportunities. These configurations of affect show a tendency towards reaction, as the individual is perceiving changes in the environment and making efforts to connect the dots (Baron and Eansley, 2006). These configurations of affect cover the spectrum in terms of valence and activation levels, signaling the experience of an affective complexivity, which favors creativity and making unusual connections (Fong, 2006). Scared and irritable, both affect dimensions positioned in the high-activation unpleasure affect axis (HAUA), are the most important to opportunity recognition illustrating that the individual is actively reacting, which encourages behavior, i.e., the subsequent decision to exploit the opportunity. Raghunathan and Pham (1999) found that high-activation unpleasure affect primes behaviors to reduce uncertainty, which is important for the entrepreneur during opportunity recognition. Also, affect dimensions high in activation, either positive or negative, help to persevere in achieving creative results when facing complex tasks (To, Fisher, Ashkanasy and Rowe, 2011). This improves fluency and novelty of ideas (De Dreu, Baas and Nijstad, 2008), thus enabling opportunity recognition. Behavioral tendencies associated with HAUA include energy, effort, and perseverance (Madrid and Patterson, 2018), facilitating problem identification and opportunity recognition. These affective configurations narrow 
cognition allowing a closer understanding of the problem's etiology (Bledow et al., 2013), helping to understand the nature of the pain point and gaining empathy with potential customers.

During opportunity exploitation, the configuration of affect is notably different. Nascent entrepreneurs feel "vigilant", "inner turbulence" and a "self-direction" while deciding whether to exploit or not the opportunity. In this stage, nascent entrepreneurs are geared towards action to develop a product or service based on the opportunity recognized (Kuckertz et al., 2017). Metaphorically, the nascent entrepreneur resembles a sentinel, looking for the best ways of acting and self-motivating him/herself towards action, while being cautious and overlooking every detail to mitigate risk. While these configurations of affect show a tendency towards action, entrepreneurs are still very vigilant and precautious. Opportunity exploitation is guided through a tension between high-activation pleasant affect (HAPA) and low-activation unpleasant affect (LAUA), as the Olden algorithm scores show ("determined" HAPA OE RI OldenAlg = 17.39; and "ashamed" LAUA OE RI OldenAlg = 15.39). High-activation positive affect is beneficial for creative activities and proactive endeavors (Madrid and Patterson, 2018), and thus is likely to drive opportunity exploitation. At the same time, LAUA favors narrowing the focus of attention, bottom-up information processing, and systematic and effortful thinking (Madrid and Patterson, 2018), which is necessary to assess the feasibility of the opportunity (Santos et al., 2015; Ivanova et al., 2018). Feelings of low-activated negative affect may also lead to creativity by fear of failure or loss (Bindl et al., 2012), which may help individuals to leverage and bootstrap resources as needed to launch their ventures. This LAUA affective configuration facilitates problem identification with closer attention and promotes high concentration on the relevant information, benefiting an informed and conscient opportunity exploitation.

These results contribute to the literature that examines the relationship between affect and entrepreneurial cognition (e.g. Foo et al., 2009) by showing that the affect circumplex model (Russell, 2003; Warr et al., 2014) is an appropriate framework to understand the affective turmoil experienced by nascent entrepreneurs. While prior studies focused on either positive, negative or mixed affect (Podoynitsyna et al., 2012; Zampetakis et al., 2015) relevant for opportunities and tended to ignore the role of arousal, we show that opportunity recognition and exploitation are not always black or white. Yet, they integrate a complex palette of shades and gradients.

We also illustrate the relevance of nonlinear methods in exploring the complex relationship between cognitive processes and affect, answering to Shepherd's (2015) call for entrepreneurship research that is more interactive, activity based and cognitively hot. Specifically, our use of nonlinear methods enabled us to capture the complexity of the affective turmoil experienced by entrepreneurs, which previously was reduced to the dichotomy between positive and negative valence.

\subsection{Limitations, future research and practical implications}

This study has limitations. First, recalling affect experienced during opportunity recognition and exploitation can include bias and may be influenced by previous experience (Simon et al., 2000), past memory recalls (Golden, 1992) or bias and distortion of the self-reported accounts (Podsakoff and Organ, 1986). Also, affective states were only measured once, whereas future research should follow entrepreneurs over time. Future research should monitor entrepreneurs who are engaged in opportunity recognition and exploitation over time. This would allow tracking affect dimensions in real-time (daily or weekly). Second, we did not include any anticipated affect relevant for entrepreneurship (Zampetakis et al., 2015) such as anticipatory passion (Cohen et al., 2019). Future research can explore the emergence of anticipated affect configurations and their effect on new venture ideas (Frederiks et al., 2019) using a nonlinear perspective. Novel research is also needed to understand affective diversity in new venture teams (e.g. de Mol et al., 2019) and its implications for early stage startup outcomes. Third, we limited our criteria variables to opportunity recognition and exploitation, leaving opportunity evaluation unexplored. We incentivize future research to address the role of affect configurations on opportunity evaluation (e.g., Foo, 2011; Grichnik et al., 2010). Also, serial entrepreneurs should be analyzed, as prior research pointed towards substantial changes on emotional reactions of entrepreneurs with more experience (Podoynitsyna et al., 2012). Fourth, due to the limitations of our sample size, we encourage future research to utilize big data sets and artificial intelligence methods such as computerized language analysis, which is particularly useful to uncover emotions and affect (Obschonka and Audretsch, 2019; Lévesque et al., 2020).

Our findings regarding the configurations of affect associated with opportunity recognition and evaluation provide a holistic overview of the affective turmoil experienced by nascent entrepreneurs. The emerged configurations of affect are idiosyncratic and constitute event privacies according to the MacMillan and Katz (1992) framework of idiosyncratic milieus of entrepreneurship research. To better cope with this idiosyncrasy, we adopted theories from another field and used nonlinear data analysis methods to capture complex patterns of affect. Due to the idiosyncrasy inherent to the entrepreneurial experience, we do not expect that the precise configurations of affect will be replicable in other samples. However, the pattern of the overarching results referring to the quadrants of affect that are more related to opportunity recognition and exploitation, are expected to be generalized to nascent entrepreneurs recalling their affect. We encourage future research along this line. Specifically, HAUA affect dimensions are expected to be more associated with opportunity recognition, while HAPA and LAUA are expected to be more related to opportunity exploitation.

Our findings also offer practical implications. First, entrepreneurs need to recognize the role of the affective turmoil on opportunity recognition and exploitation, contrasting the entrepreneur's perspective that the decision to launch or not the venture depends upon objective characteristics. Recognizing the subjectivity and idiosyncrasy of the affective turmoil, entrepreneurs should also be aware of how their affect will influence their cognitive processes and decision making. If an entrepreneur experiences an affective configuration similar to "reactive energetic", his/her tendency to recognize an opportunity decreases. Similarly, if an entrepreneur experiences an affective configuration similar to "cautious action", his/her tendency to exploit the opportunity also decreases. Second, education should also cover the affective side of entrepreneurship by creating awareness that startup activities are not always characterized by just positive and/or negative affective experiences (Keller and Kozlinska, 2019). Students should understand this affective complexity and how it influences cognition and decision making in entrepreneurship. 


\section{Declaration of competing interest}

The authors declare that they have no known competing financial interests or personal relationships that could have appeared to influence the work reported in this paper.

\section{Acknowledgements}

This work was supported by Fundação para a Ciência e a Tecnologia, grant UIDB/00315/2020.

Appendix 1. Organization of predictors in Hidden Nodes: opportunity recognition

\begin{tabular}{|c|c|c|c|c|}
\hline & Hidden Node 1 & Hidden Node 2 & Hidden Node 3 & Hidden Node 4 \\
\hline Interested & -2.36 & 0.48 & -1.13 & -0.51 \\
\hline Relaxed & 0.23 & -0.14 & -0.81 & 1.65 \\
\hline Excited & -0.93 & 0.14 & 0.51 & 1.28 \\
\hline Upset & 2.34 & 0.67 & 1.25 & 0.54 \\
\hline Strong & -0.12 & 1.41 & -0.25 & 1.02 \\
\hline Guilty & 0.51 & -1.91 & 1.11 & 1.68 \\
\hline Scared & -0.39 & 1.59 & 9.11 & 0.57 \\
\hline Hostile & 1.40 & -0.80 & 0.21 & 1.32 \\
\hline Enthusiastic & 1.46 & 2.44 & 0.03 & 1.22 \\
\hline Proud & 0.33 & 2.60 & 0.28 & 2.32 \\
\hline Irritable & -1.57 & -3.11 & 4.57 & 2.08 \\
\hline Alert & -0.89 & -0.52 & -1.13 & 2.30 \\
\hline Ashamed & -1.08 & 1.81 & 1.50 & -0.16 \\
\hline Inspired & -0.78 & -0.59 & 1.16 & -0.50 \\
\hline Nervous & 0.23 & 1.57 & -4.19 & 1.62 \\
\hline Determined & 0.38 & -0.62 & -0.45 & 0.32 \\
\hline Attentive & -1.23 & 0.88 & -0.41 & 0.99 \\
\hline Jittery & 0.70 & -0.30 & 1.59 & 1.10 \\
\hline Active & 0.68 & -0.92 & 0.28 & 0.54 \\
\hline \multirow[t]{3}{*}{ Afraid } & 0.62 & -3.95 & -3.48 & -0.62 \\
\hline & Reactive energetic & Self-enhancement & Active screening & Serendipitous mood \\
\hline & $\mathrm{RI}=-3.56$ & $\mathrm{RI}=0.83$ & $\mathrm{RI}=1.19$ & $\mathrm{RI}=0.84$ \\
\hline
\end{tabular}

Note: cells marked in grey highlight the affect dimensions that contribute to that hidden node; values in bold indicate the strongest contributors. Relative importance (RI) is an effect size metric that specifies the importance of a predictor considering all others, providing a description of the weights of all input variables (Lucek and Ott, 1997).

Appendix 2. Organization of predictors in Hidden Nodes: opportunity exploitation

\begin{tabular}{lllll}
\hline & Hidden Node 1 & Hidden Node 2 & Hidden Node 3 & Hidden Node 4 \\
\hline Interested & -1.54 & 0.55 & -0.98 & -0.65 \\
Relaxed & 3.46 & 4.58 & -3.10 & 1.13 \\
Excited & 0.48 & -1.66 & -0.74 & 0.70 \\
Upset & -2.85 & 0.43 & -4.47 & 4.58 \\
Strong & -3.24 & 2.13 & 0.83 & 1.49 \\
Guilty & 2.09 & -8.26 & 0.48 & $\mathbf{3 . 0 7}$ \\
Scared & -0.30 & -5.60 & -0.23 & -0.13 \\
Hostile & -1.89 & 0.11 & -0.40 \\
Enthusiastic & 2.62 & 1.26 & -1.07 \\
Proud & 0.34 & -0.21 & 0.26 & 0.59 \\
Irritable & 2.52 & 3.67 & -0.32 & -1.43 \\
Alert & -1.13 & -2.06 & -1.59 & -0.95 \\
Ashamed & $\mathbf{5 . 6 4}$ & -1.56 & -0.09 & -0.90 \\
Inspired & -1.42 & -0.67 & 0.63 & 0.94 \\
Nervous & -1.31 & 1.96 & 0.60 & 1.00 \\
Determined & $\mathbf{2 . 1 5}$ & 1.40 & 0.234 & 0.10 \\
Attentive & -0.16 & -1.10 & 1.78 & 0.24 \\
Jittery & 1.01 & 0.08 & $\mathbf{0 . 8 4}$ & -2.17 \\
Active & 0.14 & -1.92 & 0.09 & -1.67 \\
Afraid & -1.37 & 1.04 & -0.39 & 0.36 \\
& Self-directon & Cautious action & Inner turbulence \\
& $\mathrm{RI}=1.80$ & $\mathrm{RI}=-1.45$ & Vigilant & RI = 2.80 \\
\hline
\end{tabular}


Note: cells marked in grey highlight the affect dimensions that contribute to that hidden node; values in bold indicate the strongest contributors. Relative importance (RI) is an effect size metric that specifies the importance of a predictor considering all others, providing a description of the weights of all input variables (Lucek and Ott, 1997).

\section{References}

Adolphs, R., Damasio, A.R., 2001. The interaction of affect and cognition: a neurobiological perspective. In: Forgas, J.P. (Ed.), Handbook of Affect and Social Cognition. Lawrence Erlbaum Associates Publishers, pp. 27-49.

Angie, A.D., Connelly, S., Waples, E.P., Kligyte, V., 2011. The influence of discrete emotions on judgement and decision-making: a meta-analytic review. Cognit. Emot. 25 (8), 1393-1422.

Baron, R.A., 1998. Cognitive mechanisms in entrepreneurship: why and when entrepreneurs think differently than other people. J. Bus. Ventur. 13 (4), $275-294$.

Baron, R.A., 2006. Opportunity recognition as pattern recognition: how entrepreneurs 'connect the dots' to identify new business opportunities. Acad. Manag. Perspect. 20 (1), 104-119.

Baron, R.A., 2008. The role of affect in the entrepreneurial process. Acad. Manag. Rev. 33 (2), 328-340.

Baron, R.A., Ensley, M.D., 2006. Opportunity recognition as the detection of meaningful patterns: evidence from comparisons of novice and experienced entrepreneurs. Manag. Sci. 52 (9), 1331-1344.

Baron, R.A., Tang, J., 2011. The role of entrepreneurs in firm-level innovation: joint effects of positive affect, creativity, and environmental dynamism. J. Bus. Ventur. 26 (1), 49-60.

Baron, R.A., Tang, J., Hmieleski, K.M., 2011. The downside of being 'up': entrepreneurs' dispositional positive affect and firm performance. Strategic Entrepreneurship Journal 5 (2), 101-119.

Beck, M.W., 2018. NeuralNetTools: visualization and analysis tools for neural networks. J. Stat. Software 85 (11), 1-20.

Bindl, U.K., Parker, S.K., Totterdell, P., Hagger-Johnson, G., 2012. Fuel of the self-starter: how mood relates to proactive goal regulation. J. Appl. Psychol. 97 (1), 134. Blanchette, I., Richards, A., 2010. The influence of affect on higher level cognition: a review of research on interpretation, judgement, decision making and reasoning. Cognit. Emot. 24 (4), 561-595.

Bledow, R., Rosing, K., Frese, M., 2013. A dynamic perspective on affect and creativity. Acad. Manag. J. 56 (2), $432-450$.

Busenitz, L.W., Barney, J.B., 1997. Differences between entrepreneurs and managers in large organizations: biases and heuristics in strategic decision-making. J. Bus. Ventur. 12 (1), 9-30.

Cardon, M.S., Foo, M.D., Shepherd, D., Wiklund, J., 2012. Exploring the heart: entrepreneurial emotion is a hot topic. Enterpren. Theor. Pract. 36 (1), 1-10. Cardon, M.S., Wincent, J., Singh, J., Drnovsek, M., 2009. The nature and experience of entrepreneurial passion. Acad. Manag. Rev. 34 (3), $511-532$.

Churchill, N.C., Bygrave, W.D., 1990. The entrepreneurship paradigm (II): chaos and catastrophes among quantum jumps? Enterpren. Theor. Pract. 14 (2), 7-30.

Cohen, D.A., Cardon, M.S., Singh, J., 2019. July). Anticipatory entrepreneurial passion and its role in shaping affect/effort of nascent entrepreneurs. Acad. Manag. Proc. https://doi.org/10.5465/AMBPP.2019.13665abstract.

Damasio, A., 2018. The Strange Order of Things: the Life, Feelings and the Making of Culture. Pantheon Books, New York, NY.

Davis, B.C., Hmieleski, K.M., Webb, J.W., Coombs, J.E., 2017. Funder's positive affective reactions to entrepreneurs' crowdfunding pitches: the influence of perceived product creativity and entrepreneurial passion. J. Bus. Ventur. 32 (1), 90-106.

De Dreu, C.K., Baas, M., Nijstad, B.A., 2008. Hedonic tone and activation level in the mood-creativity link: toward a dual pathway to creativity model. J. Pers. Soc. Psychol. 94 (5), 739

de Mol, E., Cardon, M.S., de Jong, B., Khapova, S.N., Elfring, T., 2019. Entrepreneurial passion diversity in new venture teams: an empirical examination of short-and long-term performance implications. J. Bus. Ventur. https://doi.org/10.1016/j.jbusvent.2019.105965.

Doern, R., Goss, D., 2014. The role of negative emotions in the social processes of entrepreneurship: power rituals and shame-related appeasement behaviors. Enterpren. Theor. Pract. 38 (4), 863-890.

Douglas, E.J., Shepherd, D.A., Prentice, C., 2020. Using fuzzy-set qualitative comparative analysis for a finer-grained understanding of entrepreneurship. J. Bus. Ventur. 35 (1), 105970.

Eckhardt, J.T., Shane, S.A., 2003. Opportunities and entrepreneurship. J. Manag. 29 (3), 333-349.

Fodor, O.C., Pintea, S., 2017. The "emotional side" of entrepreneurship: a meta-analysis of the relation between positive and negative affect and entrepreneurial performance. Front. Psychol. 8, 1-16.

Fong, C.T., 2006. The effects of emotional ambivalence on creativity. Acad. Manag. J. 49 (5), 1016-1030.

Foo, M.D., 2011. Emotions and entrepreneurial opportunity evaluation. Enterpren. Theor. Pract. 35 (2), $375-393$.

Foo, M.D., Uy, M.A., Baron, R.A., 2009. How do feelings influence effort: an empirical study of entrepreneurs' affect and venture effort. J. Appl. Psychol. 94, 1086-1094.

Forgas, J.P., 1995. Mood and judgment: the affect infusion model (AIM). Psychol. Bull. 117 (1), 39.

Frederiks, A.J., Englis, B.G., Ehrenhard, M.L., Groen, A.J., 2019. Entrepreneurial cognition and the quality of new venture ideas: an experimental approach to comparing future-oriented cognitive processes. J. Bus. Ventur. 34 (2), 327-347.

Fredrickson, B.L., 2001. The role of positive emotions in positive psychology: the broaden-and-build theory of positive emotions. Am. Psychol. 56 (3), 218-226.

Fritsch, S., Guenther, F., Suling, M., Mueller, S.M., 2016. Neuralnet: Training of Neural Networks (R Package).

García, J.B.D., Puente, E.Q., Mazagatos, V.B., 2015. How affect related to entrepreneurship: a systematic review of the literature and research agenda. Int. J. Manag. Rev. 17, 191-211.

George, J.M., Zhou, J., 2007. Dual tuning in a supportive context: joint contributions of positive mood, negative mood, and supervisory behaviors to employee creativity. Acad. Manag. J. 50 (3), 605-622.

Golden, B.R., 1992. The past is the past-or is it? The use of retrospective accounts as indicators of past strategy. Acad. Manag. J. 3 (4), 848-860.

Greenwell, B.M., Boehmke, B.C., McCarthy, A.J., 2018. A Simple and Effective Model-Based Variable Importance Measure arXiv preprint arXiv:1805.04755.

Grégoire, D.A., Barr, P.S., Shepherd, D.A., 2010. Cognitive processes of opportunity recognition. Organ. Sci. 21 (2), $413-431$.

Grichnik, D., Smeja, A., Welpe, I., 2010. The importance of being emotional: how do emotions affect entrepreneurial opportunity evaluation and exploitation? J. Econ. Behav. Organ. 76 (1), 15-29.

Guastello, S.J., 2007. Nonlinear dynamics and leadership emergence. Leader. Q. 18 (4), 357-369.

Hayton, J.C., Cholakova, M., 2012. The role of affect in the creation and intentional pursuit of entrepreneurial ideas. Enterpren. Theor. Pract. 36 (1), $41-67$.

Hills, G., Shrader, R., Lumpkin, T., 1999. Opportunity recognition as a creative process. In: Reynolds, P.D., Bygrave, W.D., Manigart, S., Mason, C.M., Meyer, G.D., Sapienza, H.J., et al. (Eds.), Frontiers of Entrepreneurship Research. Babson College), Wellesley, MA, pp. $216-227$.

Hui, C.L., Lau, T.W., Ng, S.F., Chan, K.C.C., 2004. Neural network prediction of human psychological perceptions of fabric hand. Textil. Res. J. 74 (5), 375-383.

Ivanova, S., Treffers, T., Langerak, F., 2018. Emotional paths leading to opportunity desirability and feasibility beliefs through controllability. Int. Small Bus. J. 36 (5), $546-573$.

Karanika-Murray, M., Cox, T., 2010. The use of artificial neural networks and multiple linear regression in modelling work-health relationships: translating theory into analytical practice. Eur. J. Work. Organ. Psychol. 19 (4), 461-486.

Kaufmann, G., 2003. The effect of mood on creativity in the innovation process. In: Shavinina, L.V. (Ed.), The International Handbook on Innovation. Elsevier Science, Oxford, U.K., pp. 191-203 
Keller, P.G., Kozlinska, I., 2019. Entrepreneurial affect and emotions in entrepreneurship education impact research: a systematic review and research agenda. Entrepreneurship Education and Pedagogy 2 (4), 281-307.

Kuckertz, A., Kollmann, T., Krell, P., Stöckmann, C., 2017. Understanding, differentiating, and measuring opportunity recognition and opportunity exploitation. Int. J. Entrep. Behav. Res. 23 (1), 78-97.

Lévesque, M., Obschonka, M., Nambisan, S., 2020. Pursuing impactful entrepreneurship research using artificial intelligence. Entrep. Theor. Practice. https://doi.org/ $10.1177 / 1042258720927369$.

Li, H., Zhang, Y., Tong, H., Tong, Q., Liu, D., 2011. Study on psychological crisis evaluation combining factor analysis and neural networks. Psychology 2 (2), 138-142. Lichtenstein, B.M.B., 1999. A dynamic model of non-linearity in entrepreneurship. J. Bus. Entrepren. 11, 27-43.

Lorenz, E.N., 1993. The Essence of Chaos. University of Washington Press, Seattle.

Lucek, P.R., Ott, J., 1997. Neural network analysis of complex traits. Genetic Epidemiol. 14 (6), 1101-1106.

MacMillan, I.C., Katz, J.A., 1992. Idiosyncratic milieus of entrepreneurial research: the need for comprehensive theories. J. Bus. Ventur. 7 (1), 1-8.

Madrid, H.P., Patterson, M.G., 2018. Affect and creativity. In: Reiter-Palmon, R., Kennel, V., Kaufman, J.C. (Eds.), Individual Creativity in the Workplace. Elsevier, Amsterdam, Netherlands, pp. 245-265.

McKelvey, B., 2004. Toward a complexity science of entrepreneurship. J. Bus. Ventur. 19 (3), 313-341.

McMullen, J.S., Shepherd, D.A., 2006. Entrepreneurial action and the role of uncertainty in the theory of the entrepreneur. Acad. Manag. Rev. 31 (1), 132-152.

Obschonka, M., Audretsch, D.B., 2019. Artificial intelligence and big data in entrepreneurship: a new era has begun. Small Bus. Econ. https://doi.org/10.1007/s11187019-00202-4.

Olden, J.D., Joy, M.K., Death, R.G., 2004. An accurate comparison of methods for quantifying variable importance in artificial neural networks using simulated data. Ecol. Model. 178 (3-4), 389-397.

Podoynitsyna, K., Van der Bij, H., Song, M., 2012. The role of mixed emotions in the risk perception of novice and serial entrepreneurs. Enterpren. Theor. Pract. 36 (1), 115-140.

Podsakoff, P.M., Organ, D.W., 1986. Self-reports in organizational research: problems and prospects. J. Manag. 12 (4), $531-544$.

Raghunathan, R., Pham, M.T., 1999. All negative moods are not equal: motivational influences of anxiety and sadness on decision making. Organ. Behav. Hum. Decis. Process. 79 (1), 56-77.

Remington, N.A., Fabrigar, L.R., Visser, P.S., 2000. Reexamining the circumplex model of affect. J. Pers. Soc. Psychol. 79 (2), 286.

Rueff-Lopes, R., Navarro, J., Caetano, A., Silva, A.J., 2017. Forecasting the influence of customer-related micro-events on employees' emotional, attitudinal and physiological responses. Eur. J. Work. Organ. Psychol. 26 (6), 779-797.

Russell, J.A., 1980. A circumplex model of affect. J. Pers. Soc. Psychol. 39 (6), 1161-1178.

Russell, J.A., 2003. Core affect and the psychological construction of emotion. Psychol. Rev. 110 (1), $145-172$.

Santos, S.C., Caetano, A., Baron, R., Curral, L., 2015. Prototype models of opportunity recognition and the decision to launch a new venture: identifying the basic dimensions. Int. J. Entrep. Behav. Res. 21 (4), 510-538.

Shane, S., Venkataraman, S., 2000. The promise of entrepreneurship as a field of research. Acad. Manag. Rev. 25 (1), $217-226$.

Shepherd, D.A., 2015. Party on! A call for entrepreneurship research that is more interactive, activity based, cognitively hot, compassionate, and prosocial. J. Bus. Ventur. 30 (4), 489-507.

Shepherd, D.A., Patzelt, H., 2018. Entrepreneurial Cognition: Exploring the Mindset of Entrepreneurs. Palgrave Macmillan, Cham.

Simon, M., Houghton, S.M., Aquino, K., 2000. Cognitive biases, risk perception, and venture formation: how individuals decide to start companies. J. Bus. Ventur. 15 (2), 113-134.

So, J., Achar, C., Han, D., Agrawal, N., Duhachek, A., Maheswaran, D., 2015. The psychology of appraisal: specific emotions and decision-making. J. Consum. Psychol. 25 (3), 359-371.

Tang, J., Kacmar, K.M.M., Busenitz, L., 2012. Entrepreneurial alertness in the pursuit of new opportunities. J. Bus. Ventur. 27 (1), $77-94$.

To, M.L., Fisher, C.D., Ashkanasy, N.M., Rowe, P.A., 2012. Within-person relationships between mood and creativity. J. Appl. Psychol. 97 (3), 599.

Treffers, T., Klyver, K., Nielsen, M.S., Uy, M.A., 2019. Feel the commitment: from situational emotional information to venture goal commitment. Int. Small Bus. J. 37 (3), 215-240.

Uy, M.A., Sun, S., Foo, M.D., 2017. Affect spin, entrepreneurs' well-being, and venture goal progress: the moderating role of goal orientation. J. Bus. Ventur. 32 (4), 443-460.

Warr, P., Bindl, U.K., Parker, S.K., Inceoglu, I., 2014. Four-quadrant investigation of job-related affects and behaviours. Eur. J. Work. Organ. Psychol. 23 (3), $342-363$.

Watson, D., Clark, L.A., Tellegen, A., 1988. Development and validation of brief measures of positive and negative affect: the PANAS scales. J. Pers. Soc. Psychol. 54 (6), 1063-1070.

Welpe, I.M., Spörrle, M., Grichnik, D., Michl, T., Audretsch, D.B., 2012. Emotions and opportunities: the interplay of opportunity evaluation, fear, joy, and anger as antecedent of entrepreneurial exploitation. Enterpren. Theor. Pract. 36 (1), 69-96.

Yegnanarayana, B., 2009. Artificial Neural Networks. PHI Learning Pvt. Ltd.

Zajonc, R.B., 1980. Feeling and thinking: preferences need no inferences. Am. Psychol. 35 (2), 151-175.

Zampetakis, L.A., Kafetsios, K., Moustakis, V., 2017. Using emotional persuasion for changing attitudes towards entrepreneurship: an interpersonal perspective. J. Bus. Ventur. Insights 7, 50-54.

Zampetakis, L.A., Lerakis, M., Kafetsios, K., Moustakis, V., 2015. Investigating the emotional impact of entrepreneurship programs. J. Bus. Ventur. Insights 4, 38-41. 